\title{
Parameterization of a numerical 2-D debris flow model with entrainment: a case study of the Faucon catchment, Southern French Alps
}

\author{
H. Y. Hussin ${ }^{1}$, B. Quan Luna ${ }^{2}$, C. J. van Westen ${ }^{3}$, M. Christen ${ }^{4}$, J.-P. Malet ${ }^{5}$, and Th. W. J. van Asch ${ }^{6}$ \\ ${ }^{1}$ CNR-IRPI, via Madonna Alta 126, 06128 Perugia, Italy \\ ${ }^{2}$ NGI, Norwegian Geotechnical Institute - ICG, International Centre for Geohazards, Sognsveien 72, 0855, Oslo, Norway \\ ${ }^{3}$ Faculty of Geo-Information Science and Earth Observation (ITC), University of Twente, P.O. Box 6, 7500 AA Enschede, \\ The Netherlands \\ ${ }^{4}$ WSL, Swiss Federal Institute for Snow and Avalanche Research SLF, Flüelastrasse 11, 7260 Davos Dorf, Switzerland \\ ${ }^{5}$ Institut de Physique du Globe de Strasbourg, CNRS UMR 7516, Université de Strasbourg / EOST, 5 rue René Descartes, \\ 67084 Strasbourg Cedex, France \\ ${ }^{6}$ Faculty of Geosciences, Utrecht University, Utrecht, The Netherlands \\ Correspondence to: H. Y. Hussin (haydar.hussin@irpi.cnr.it)
}

Received: 8 November 2011 - Revised: 16 August 2012 - Accepted: 30 August 2012 - Published: 18 October 2012

\begin{abstract}
The occurrence of debris flows has been recorded for more than a century in the European Alps, accounting for the risk to settlements and other human infrastructure that have led to death, building damage and traffic disruptions. One of the difficulties in the quantitative hazard assessment of debris flows is estimating the run-out behavior, which includes the run-out distance and the related hazard intensities like the height and velocity of a debris flow. In addition, as observed in the French Alps, the process of entrainment of material during the run-out can be 10-50 times in volume with respect to the initially mobilized mass triggered at the source area. The entrainment process is evidently an important factor that can further determine the magnitude and intensity of debris flows. Research on numerical modeling of debris flow entrainment is still ongoing and involves some difficulties. This is partly due to our lack of knowledge of the actual process of the uptake and incorporation of material and due the effect of entrainment on the final behavior of a debris flow. Therefore, it is important to model the effects of this key erosional process on the formation of runouts and related intensities. In this study we analyzed a debris flow with high entrainment rates that occurred in 2003 at the Faucon catchment in the Barcelonnette Basin (Southern French Alps). The historic event was back-analyzed using the Voellmy rheology and an entrainment model imbedded
\end{abstract}

in the RAMMS 2-D numerical modeling software. A sensitivity analysis of the rheological and entrainment parameters was carried out and the effects of modeling with entrainment on the debris flow run-out, height and velocity were assessed.

\section{Introduction}

Debris flows are one of the types of mass movements that cause significant damage to properties and loss of lives, as they often occur in those parts of mountainous environments that are most utilized by human activities, e.g. alluvial fans and floodplains. The expansion of infrastructure for tourism and winter recreational purposes has further increased the risk of people and property being affected by the debris flows. The quantitative hazard assessment of debris flows is still in its initial stage, partly due to the difficulties in establishing scenarios with realistic estimations of the temporal and spatial probability of occurrence of debris flow events, and the quantification of the physical vulnerability of infrastructure in relation to the intensity of the event. Therefore, estimating the debris flow run-out and related intensities (e.g. height and velocity) is important to link the hazard with the vulnerability and related losses of elements at risk to debris flows. 
A considerable number of approaches have been developed to predict the run-out of debris flows, which can be generally divided into three different groups: empiricalstatistical methods (Hsu, 1978; Corominas, 1996; Rickenmann, 1999), analytical methods (Sassa, 1988; Hungr, 1995; Hürlimann et al., 2007) and numerical methods (Denlinger and Iverson, 2004; Crosta et al., 2009; Hungr and McDougall, 2009). The numerical methods have the strong advantage of being able to calculate the movement of the flow over irregular topographic terrains. Furthermore, they can compute intensity related parameters like the flow depth and impact pressure at every point in the flow path which can be coupled to vulnerability functions for quantitative risk assessment (Quan Luna et al., 2011).

As part of the numerical methods, dynamic continuum models use fluid mechanics applying conservation equations of mass, momentum and energy. These equations describing the debris flow dynamic motion are further integrated with respect to the flow depth to create an approach called depthaveraging. Dynamic models can be either 1-D models that move the flow in only one spatial dimension as a cross section of a single pre-defined width or 2-D models that move the flow in two dimensions, considering the topography in the plan surface and cross-section. Rheology is used in dynamic models to further describe the frictional behavior of the debris flow material. What is essential in dynamic continuum modeling is the choice of an accurate rheology (Rickenmann, 2005). The most common rheologies used in dynamic models are: "Frictional" (or "Coulomb") resistance (Hungr and McDougall, 2009); the frictional-turbulent "Voellmy" resistance (Voellmy, 1955); the visco-plastic "Bingham" (or "Herschel-Bulkey") resistance (Coussot, 1997; Malet et al., 2004) and the "Quadratic" resistance (O'Brien et al., 1993). The Voellmy model has found good results in debris flow back-analysis and is one of the most widely used rheologies to simulate debris flows (Ayotte and Hungr, 2000; Hürlimann et al., 2003; Rickenmann et al., 2006; Pirulli and Sorbino, 2008; Hungr and McDougall, 2009). Additionally, the need for only two parameters makes the Voellmy model easy to use and calibrate with historic events.

A key feature of debris flows observed in many areas is the important effect of entrainment (channel path and torrent flanks material) during the run-out phase. Entrainment mechanisms are capable of changing the mobility of the flow, through rapid changes of the flow volume and of its rheological behavior (Iverson, 1997; McDougall and Hungr, 2005; Takahashi, 2009). For example, in the Barcelonnette Basin (South French Alps), the entrained materials may accumulate 10-50 times in volume with respect to the initially mobilized mass because of the flowing along a very erodible substratum composed of black marls (Remaître et al., 2005a, b). The entrainment process is evidently an important factor that can further determine the magnitude and intensity of debris flows. Therefore, the challenge in dynamic run-out modeling of debris flows is to include the entrainment because mod- els that use a constant volume during the motion of the flow ignore this process and are therefore not able to accurately forecast the characteristics of debris flows with high entrainment rates (Quan Luna et al., 2012). This especially applies to channelized debris flows occurring in heterogeneous torrential watersheds that are characterized by various geological settings and superficial surface deposits (Crosta et al., 2009).

In the past decade several dynamic run-out models have been developed that introduce entrainment modeling. These models generally use "processed-based entrainment rates" (Crosta et al., 2003; D'Ambrosio et al., 2003; Medina et al., 2008) where the amount of entrained material is calculated by prescribed algorithms considering the material properties, or use "defined entrainment rates" (Chen and Lee, 2007; Beguería et al., 2009; Hungr and McDougall, 2009; Pastor et al., 2009) where the amount of material is specified by the user. Positive developments are being made to study and incorporate the entrainment process in dynamic numerical modeling of debris flows. However, it is also important to test the applicability and flexibility of these models to see how well they reproduce debris flows with high entrainment rates, especially in areas where they have not been originally used for calibration or back-analysis.

In this research we conducted a back-analysis of a debris flow with the RAMMS 2-D dynamic run-out model (Christen et al., 2010) using the Voellmy rheology and an entrainment method based on the work of Sovilla et al. (2006). The entrainment rate was user defined according to reports of the historical event, image interpretation and field-studies. We also produced 120 debris flow run-outs as part of a sensitivity analysis of the Voellmy and entrainment parameters to study their effects on possible scenarios of debris-flow extents, deposit volumes, flow heights and velocities, which are intensity outputs required in the quantitative hazard assessment of debris flows. The obtained results show the advantage of including the entrainment process while modeling a debris flow event because a much better estimate of run-out and deposited volumes are obtained. However, a disadvantage is that the resistance parameters (rheological parameters) are no longer the only source of uncertainty but also soils depths and other entrainment parameters.

\section{Study area}

Channelized debris flows have been extensively studied in the European Alps. One of these locations, where data is available on past debris flow events, is the Barcelonnette Basin in the South French Alps (Flageollet et al., 1999; Maquaire et al., 2003; Malet et al., 2005; Remaître and Malet, 2010). The region has experienced since the 17th century extensive clear cutting of forests on slopes. This in turn has made the area more susceptible to debris flow hazards. The occurrence of debris flows have been recorded over more 


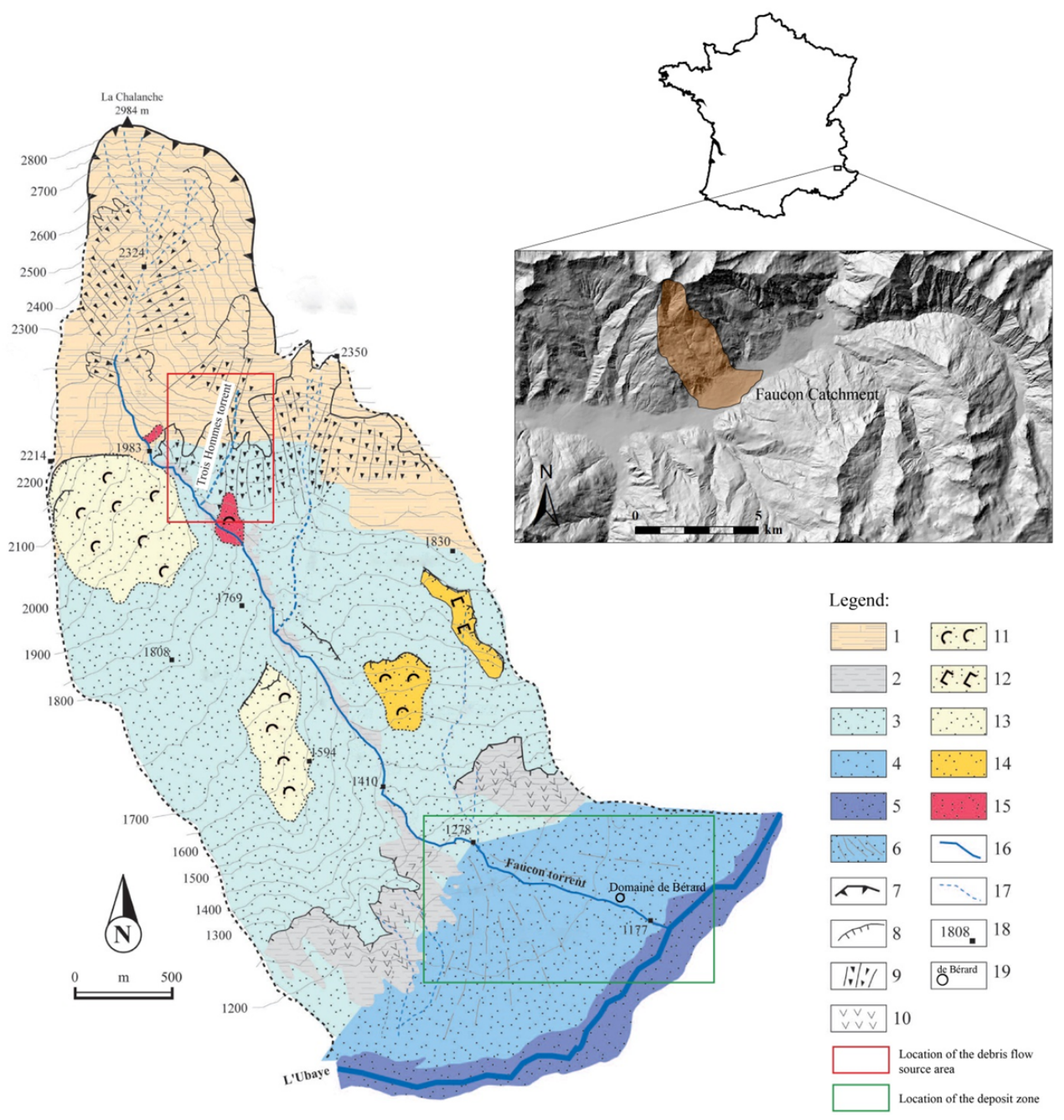

Fig. 1. Location of the Barcelonnette basin and a morphological sketch of the Faucon catchment study area (modified from Remaître, 2006). Legend: (1) Sheet thrust, (2) Black marls, (3) Quaternary deposit, (4) Torrential deposit, (5) Alluvial deposit (Ubaye), (6) Torrential fan, (7) Cirque, (8) Scarp, (9) Active scree, (10) Gully, (11) Rotational landslide, (12) Translational landslide, (13) Fossilized landslide deposit, (14) Dormant landslide deposit, (15) Active landslide deposit, (16) Perennial flow, (17) Intermittent flow, (18) Elevation spot, (19) Settlement. The red box indicates the location of the last major debris flow source area and the green box is the location of the deposit zone.

than a century in the region, becoming a threat to settlements and human infrastructure, leading to building damage and traffic disruptions (Malet et al., 2005). Some of the most recent and abundantly documented debris flows are those that occurred in the Faucon catchment in 1996 and 2003, causing significant damage to roads, bridges and properties.

The Faucon catchment is part of the Faucon-deBarcelonnette municipality located in the Barcelonnette Basin, Southern French Alps (Fig. 1). The catchment covers an area of approximately $10.5 \mathrm{~km}^{2}$, with an elevation ranging from 1130 to $2984 \mathrm{~m}$ a.s.1 and is comprised of a $5500 \mathrm{~m}$ long steep channel discharging into the Ubaye River. The upper part of the catchment ( $>1900 \mathrm{~m}$ a.s.l.) is made up of sheet thrusts of faulted sandstones and calcareous sandstones with extensive scree slopes. The central part (1300-1900 m a.s.l.) consists of Callovo-Oxfordian black marls (Terres Noires) outcropping at the side of the torrent. However, the marls in most of the central parts are covered by Quaternary deposits (with a sandy-silt matrix) composed of mixtures of landslide deposits (fossilized, dormant and active), scree debris and moraine deposits. The debris fan $(<1280 \mathrm{~m}$ a.s.l. $)$ has an area of approximately $2 \mathrm{~km}^{2}$ and its slope ranges from $4^{\circ}$ to $9^{\circ}$. The fan further consists of a mixture of torrential and fluvial permeable debris deposits due to a combination of active fluvial and debris flow processes. The Faucon catchment has experienced a total of fourteen debris flows since 1850 (Remaitre et al., 2009). 


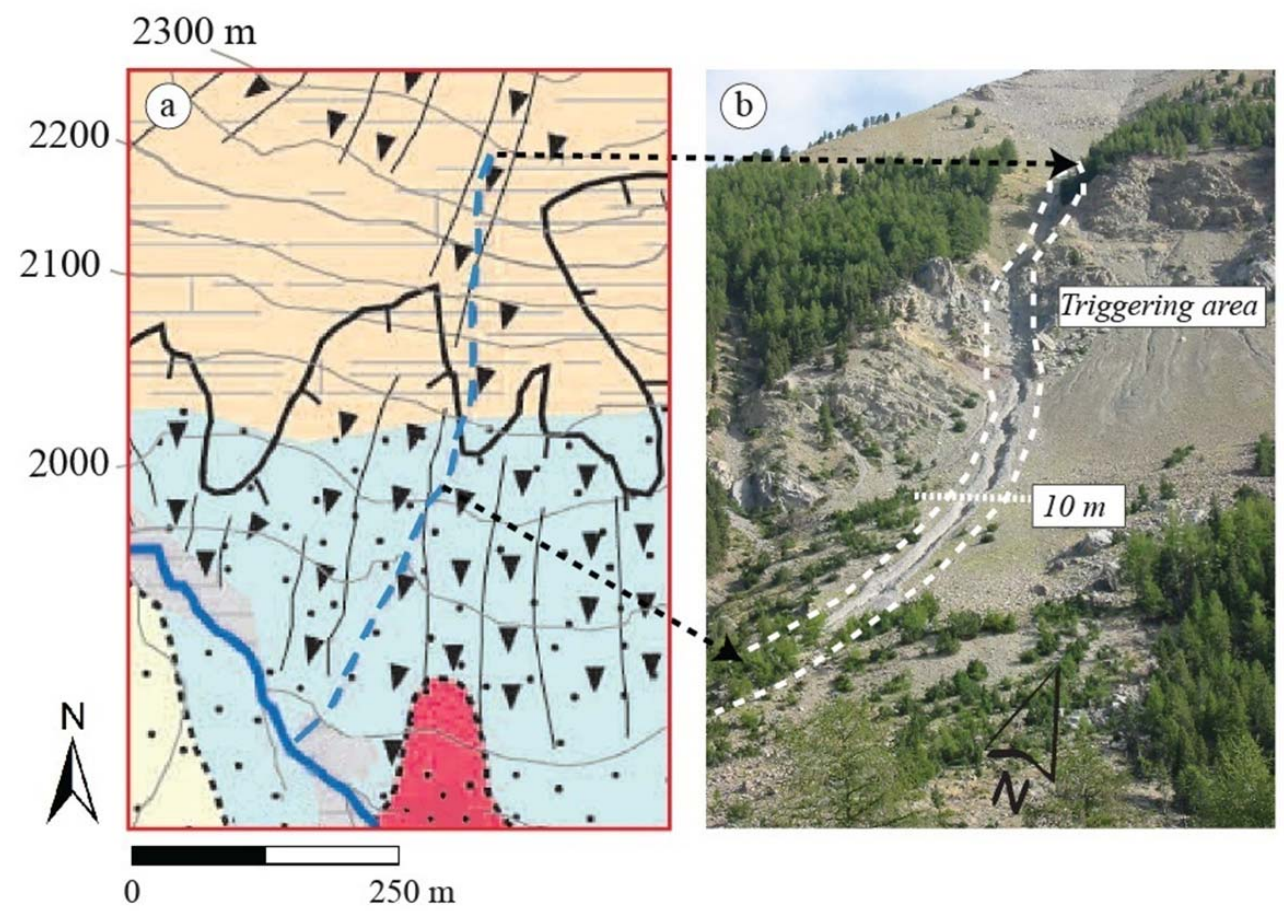

Legend:

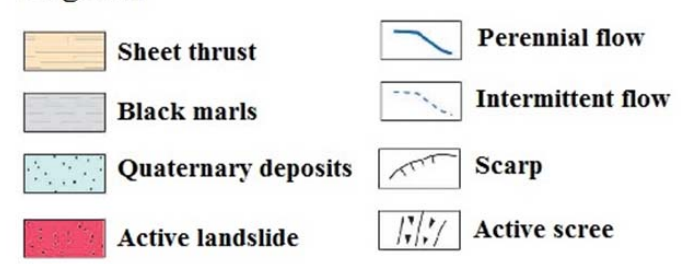

Fig. 2. (a) Morphology of the Trois Hommes source area as indicated by the red box in Fig. 1, and (b) a photograph of the torrent created by the 2003 debris flow source in the Trois Hommes scree deposits (modified from Remaitre, 2006).

\section{The 2003 debris flow and previous modeling}

The most recent debris flow occurred on the 5th of August 2003 and caused substantial damage to residential buildings located on the debris fan directly next to the Faucon stream. The triggering event was an intense rainfall, including hail, after a severe drought in the area. The east flank of the Faucon torrent contributed to the debris flow volume (Fig. 2). This includes the Trois Hommes area and the upper part of the Champerousse torrent (which is a tributary of the Faucon torrent). The source area facilitated strong incision in scree slopes. The total volume of mobilized material in the source areas, with the solid and fluid fraction combined, was estimated to range from 14000 to $17000 \mathrm{~m}^{3}$ (Remaître et al., 2009). This is substantially smaller than the total estimated deposited volume of 83000 to $95000 \mathrm{~m}^{3}$. The difference between the source area volume and the total deposit volume of the debris flow is due to extensive entrainment along the debris flow transport zone, which is around $3500 \mathrm{~m}$ long and has an average gradient of $15^{\circ}$. Further observations indi- cated that the entrained depth in the transport zone ranged from 0.5 to $4 \mathrm{~m}$ (Remaitre et al., 2009). The torrent channel running through the debris fan (Fig. 3) was mostly filled by the 2003 event. Eyewitness accounts indicated that the debris flow travelled downstream in separate surges. The final and larger surge of the debris flow was 5 to $6 \mathrm{~m}$ high and overtopped the torrent banks at a bridge of the V.C. 3 road. The surge caused damage to several houses at the hamlet "Domaine de Bérard" and deposited 1 to $2 \mathrm{~m}$ of debris on the left bank, with no injuries to residents in their houses at the time. The debris flow further continued downstream to block off the main road R.D. 900, causing alteration of the traffic for several hours.

Previous studies have analyzed the 2003 debris flow in terms of sediment and flow rheology and performed some numerical run-out modeling in 1-D and 2-D using different approaches (Remaître, 2006; Remaître et al., 2008; Beguería et al., 2009; Remaître et al., 2009; Remaître and Malet, 2010; Quan Luna et al., 2012). Remaitre et al. (2008) applied the JDFM-1 D debris run-out model (van Asch et al., 2004) 
which used the Bingham viscoplastic rheology. They incoprorated entrainment through an empircal approach (Rickenmann et al., 2003) using critical flow heights and distance to the flow front. Beguería et al. (2009) reproduced the 2003 event with the MassMov2-D model where the CoulombBingham viscoplastic rheology was applied. The model took the final $300 \mathrm{~m}$ of the deposit zone into account and did not include the effects of entrainment in the transport zone. However, the advantage of the 2-D model was that the divergence and the overtopping of the debris flow over its channel banks could be spatially replicated and showed good results with respect to the deposit heights and their extent on the debris fan. The most recent modeling of the 2003 debris flow by Quan Luna et al. (2012) included the process of entrainment. The entrainment method carried out in a 1-D model was based on the calculation of a factor of safety of an erodible soil depth by calculating the changes in stresses and pore water pressures from the incoming flow and undrained loading of the erodible soil layer.

The run-out models mentioned above have all used viscoplastic fluid rheologies (e.g. Hershel-Bulkley, CoulombBingham model) to model the 2003 Faucon debris flow. This is due to the high amount of fine sediment content in the debris flow and the good results found in the reproduction of these kinds of flows with visco-plastic rheologies (Remaitre et al., 2005b). However, there are some reasons for the choice of the RAMMS model with its embedded Voellmy rheology in our study. Firstly, dynamic debris flow modeling with entrainment in two dimensions (2-D) has not been carried out before in the Faucon. Secondly, the RAMMS numerical entrainment method, in contrast with semi-empirical methods mentioned earlier, approximates flow and basal stresses by using the mean velocity to accelerate the new entrained material at the head of the flow (Sovilla et al., 2006). Finally, the Voellmy rheology has been found to be stable and robust for several applications of 2-D modeling in a variety of geological settings in the European Alps and has shown to accurately simulate the velocity and depositional patterns of debris flows (Ayotte and Hungr, 2000; Hürlimann et al., 2003; Rickenmann et al., 2006; Pirulli and Sorbino, 2008; Hungr and McDougall, 2009).

\section{The RAMMS model and governing equations}

RAMMS (Rapid Mass Movements) is a dynamic numerical modeling software package developed by the Swiss Federal Institute for Snow Avalanche Research (WSL/SLF) originally to model snow avalanches (Casteller et al., 2008; Christen et al., 2010; Bühler et al., 2011; Fischer et al., 2012). However, it has also been applied to model other types of mass movements like lahars (Quan Luna, 2007), rock avalanches (Allen et al., 2009; Schneider et al., 2010) and debris flows (Cesca and D'Agostino, 2006; Kowalski, 2008; Graf and McArdell, 2011; Hussin, 2011). The 2-D model is capable of predicting the run-out path, velocities, flow heights and impact pressures in a two and three dimensional environment. The flow model is a generalization of the quasi one-dimensional model, as discussed by Bartelt et al. (1999). RAMMS uses the Voellmy-Salm fluid flow continuum model (Salm, 1993) based on the Voellmy-fluid flow law (Voellmy, 1955) and describes the debris flow as a hydraulic-based depth-average continuum model. The flow resistance is divided into a dry-Coulomb friction $(\mu)$ and a viscous resistance turbulent friction $(\xi)$.

The RAMMS environment uses three dimensions: $x$ and $y$ are the directions of the mass movement flowing down the topographic surface and the elevation is given by $z(x, y)$, which is perpendicular to the profile. The gravitational acceleration vector in the three directions is $g=\left(g_{x}, g_{y}, g_{z}\right)$ and the time component is defined as $t$. The flow is moved in an unsteady and non-uniform motion and is characterized by two main flow parameters, which are the flow height $H(x, y, t)(\mathrm{m})$ and the mean velocity $U(x, y, t)(\mathrm{m} / \mathrm{s})$. The initial height is determined by the user when defining the source area of the debris flow as a polygon. The Voellmy-Salm model uses the following mass balance equation:

$\partial_{t} H+\partial_{x}\left(\mathrm{HU}_{x}\right)+\partial_{y}\left(\mathrm{HU}_{y}\right)=Q(x y t)$,

where $U_{x}$ and $U_{y}$ are the velocities in the $x$ and $y$ directions respectively, and $Q(x, y, t)(\mathrm{m} / \mathrm{s})$ is the mass production source term, also called the entrainment rate $(Q>0)$ or deposition rate $(Q<0)$ (Christen et al., 2010). The depth-averaged momentum balance equations in the $x$ and $y$ directions are respectively given by:

$$
\begin{aligned}
& \partial_{t}\left(\mathrm{HU}_{x}\right)+\partial_{x}\left(c_{x} \mathrm{HU}_{x}^{2}+g_{z} k_{a / p} \frac{H^{2}}{2}\right) \\
& +\partial_{y}\left(\mathrm{HU}_{x} U_{y}\right)=S_{g_{x}}-S_{f_{x}}
\end{aligned}
$$

and

$$
\begin{aligned}
& \partial_{t}\left(\mathrm{HU}_{y}\right)+\partial_{y}\left(c_{y} \mathrm{HU}_{y}^{2}+g_{z} k_{a / p} \frac{H^{2}}{2}\right) \\
& , \partial_{x}\left(\mathrm{HU}_{x} U_{y}\right)=S_{g_{y}}-S_{f_{y}}
\end{aligned}
$$

where $c_{x}$ and $c_{y}$ are profile shape factors that are determined by the DEM and $k_{a / p}$ is the earth pressure coefficient that was set to 1 to model hydrostatically the flow. This was also the result found in previous studies (Bartelt et al., 1999; Christen et al., 2010). Equations (2) and (3) include the gravitational accelerations in the $x$ and $y$ directions that are respectively given by:

$S_{g_{x}}=g_{x} H$

and

$S_{g_{y}}=g_{y} H$ 

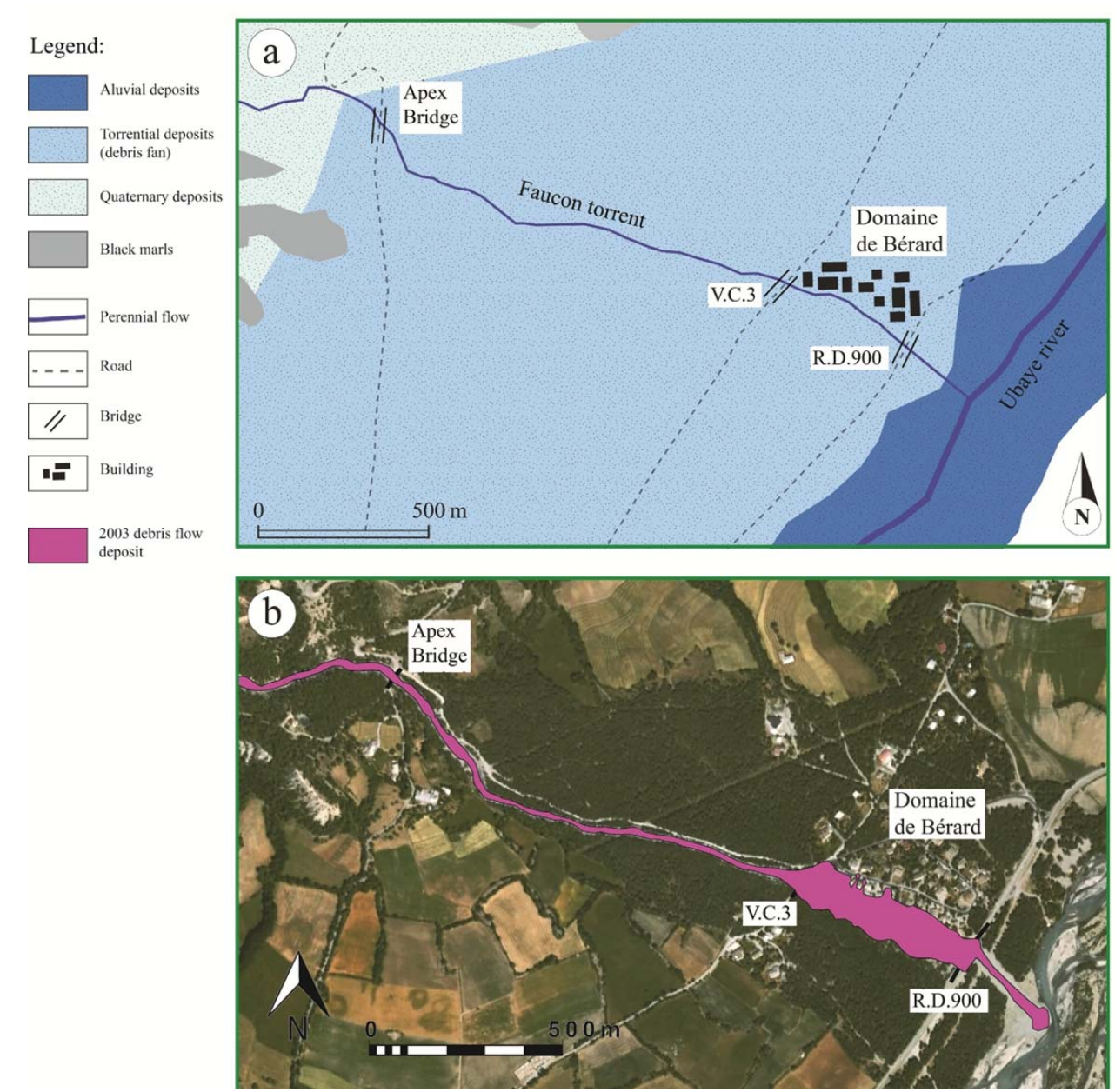

Fig. 3. (a) Sketch overview of the important elements on the Faucon debris fan with the extent of the area corresponding to the green box indicated in Fig. 1. (b) The extent of the 2003 debris flow deposit affecting the housing "Domaine de Bérard", destroying the bridge V.C.3 and closing off the R.D. 900 bridge (modified from Remaitre, 2006).

Equations (2) and (3) further contain on the right-hand side the driving frictions in the $x$ and $y$ directions and are respectively given by:

$S_{f_{x}}=n_{U_{x}}\left[\mu g_{z} H+\frac{g\|U\|^{2}}{\xi}\right]$

and

$S_{f_{y}}=n_{U_{y}}\left[\mu g_{z} H+\frac{g\|U\|^{2}}{\xi}\right]$,

where $n_{U x}$ and $n_{U y}$ are velocity directional unit vectors in the $\mathrm{x}$ and $\mathrm{y}$ directions, respectively. The total basal friction in the Voellmy-Salm model is split into a velocity independent dry-Coulomb friction coefficient $\mu$ and a velocity dependent turbulent friction coefficient $\xi\left(\mathrm{m} / \mathrm{s}^{2}\right)$. For the sake of simplicity, $\mu$ is named the "friction coefficient" and $\xi$ the "turbulent coefficient".
RAMMS is further capable of modeling entrainment throughout the debris flow path. This is done by using a ratecontrolled entrainment method which regulates the mass being entrained into the incoming debris flow and regulates the time delay to accelerate this mass to the debris flow velocity (Fig. 4). This entrainment method is mainly based on previous studies conducted by Sovilla et al. (2006). The entrainment rate $Q(x, y, t)$ is given by:

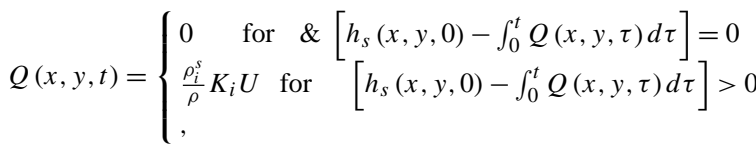

where $\rho\left(\mathrm{kg} \mathrm{m}^{-3}\right)$ is the density of the initiated incoming debris flow, $\tau$ is the shear stress, and $h_{s}(x, y, 0)(\mathrm{m})$ is the initial height of the entrainment layer at position $(x, y)$ and time $t=0 \mathrm{~s}$. The total height of the entrainment layer in RAMMS can be divided into three separate layers: $i\{1,2,3\}$ so that $h_{s}=\Sigma h_{i}$ and the density of the each layer is given by $\rho_{i}^{s}$ 


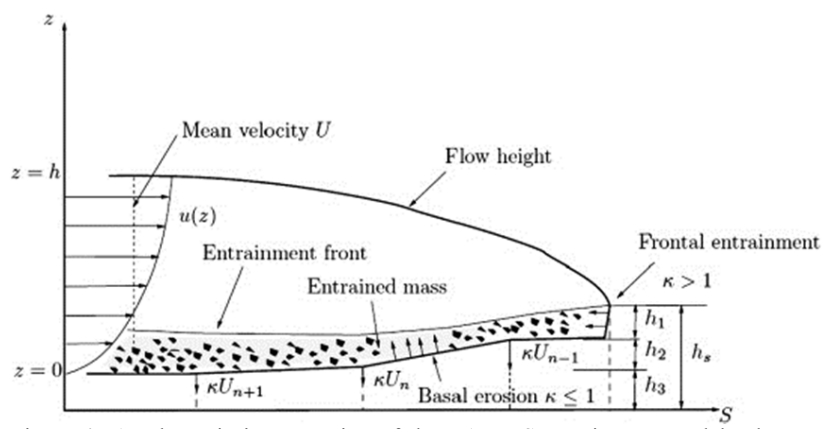

Fig. 4. A schematic interpretation of the RAMMS entrainment model. The entrainment front at each point $\mathrm{n}$ moves with the flow speed $\mathrm{U}_{n}$, where $\kappa_{i}$ is the entrainment coefficient for the ith entrainment layer. The effective entrainment rate is $\kappa_{i} \mathrm{U}_{n}$, the height is given by $z$ and $S$ is the flow direction (after Christen et al., 2010).

$\left(\mathrm{kg} \mathrm{m}^{-3}\right)$. Finally, $K_{i}$ is the dimensionless entrainment coefficient for each layer. If a single entrainment layer is chosen, then $K_{i}$ can be simply defined as $K$, as will be done further in this study.

The final inputs used in this research to model the Faucon debris flow with RAMMS are the following: a DEM, a source and entrainment area with their defined surface areas and heights; and the calibrated values for the friction coefficient $\mu$, the turbulent coefficient $\xi$ and the entrainment coefficient $K$. A detailed description on the background of the RAMMS model and all related equations can be found in Christen et al. (2010).

\section{Back-analysis of the 2003 event}

\subsection{Preparing the DEM}

Accurate topographic information is a crucial input into 2$\mathrm{D}$ modeling of channeled debris flows. Elevation differences within a model will determine the slope and thus the direction of movement of the run-out consequent changes in flow heights and velocities. The suitability of the available elevation data was tested in the RAMMS dynamic model in order to define how the data represents the actual topography of the torrent. The available DEM was generated by interpolation of digitized contour lines with a $5 \mathrm{~m}$ contour interval (Malet, 2010). Preliminary runs showed that the representation of the channel was not accurate and the modeled debris flow overtopped the channel banks at the apex of the alluvial fan, and was spreading laterally onto the fan, causing unrealistic results as compared to the 2003 event. Therefore the DEM was improved by adding the elevation of a large number of cross sections along the channel measured during a field campaign with a DGPS (Differential Global Positioning System). The result is a $5 \mathrm{~m}$ DEM that was used for the debris flow modeling in this research.

\subsection{Source area and entrainment zone identification}

The definition of the source area of the debris flow and the possible source volume was carried out according to the reported historical events combined with image interpretation and extensive fieldwork. Remaître et al. (2005a) and Kappes et al. (2011) outlined the areas that are most susceptible to trigger debris flows based on field observations and geomorphological analysis. The analysis indicates that the eastern side of the Faucon torrent slopes, and more specifically the Trois Hommes slopes, are the most susceptible to translational/rotational landslides rock falls and scree gullying, as the slopes are the steepest within the catchment and are localized near the contact among the autochthonous black marls and the allochthonous sandstones. The source areas of the 1996 and 2003 debris flow events were localized in this area. Therefore, we decided to select the same area as the source for the debris flow modeling.

RAMMS releases single or multiple source volumes, where the user must define the density of the material and further specify the area and height of each released unit. A bulk density of $1850 \mathrm{~kg} \mathrm{~m}^{-3}$ was used for the materials in both the source area and the entrainment zone in accordance with Beguería et al. (2009). The thickness of failed debris in the initiation zone was defined at $1.5 \mathrm{~m}$ based on past observations. This value was multiplied with the spatial extent of the source resulting in a source volume of $16728 \mathrm{~m}^{3}$, which is in accordance with the reported volume of the 2003 event (Remaître et al., 2008, 2009; Remaître and Malet, 2010). Figure 5 shows the demarcated polygon of the source area drawn in ArcGIS and imported into the RAMMS run-out model.

The entrainment zone and the available depth of materials that could be entrained in the channel were determined from field observations. The entrainment area within the torrent was sub-divided into five different segments according to the depth and type of material observed. As RAMMS is only capable of assigning 2 different entrainment depths with userassigned polygons, depths of 0.5 and $2.0 \mathrm{~m}$ were used as two average values (Fig. 5). The $0.5 \mathrm{~m}$ depths starts at the end of the source area until an elevation of approximately $1700 \mathrm{~m}$. From $1700 \mathrm{~m}$ to $1400 \mathrm{~m}$, the $2.0 \mathrm{~m}$ entrainment depths are more dominant and there are thicker deposits available to entrain. These areas are also more notable for the black marl (Terre Noire) outcrops (Remaître et al., 2009) (see Fig. 1). Finally, below $1400 \mathrm{~m}$ until the deposit zone, an average entrainment depth of $0.5 \mathrm{~m}$ was assigned. The total distance of the entrainment zone is approximately $3500 \mathrm{~m}$. Similar to the source area, the five channel entrainment areas were drawn in ArcGIS and imported into the RAMMS model.

\subsection{Model parameterization and calibration}

When calibrating a model that has input parameters which are continuous variables and which have a wide range of possibilities, the principle of equifinality has to be considered. 


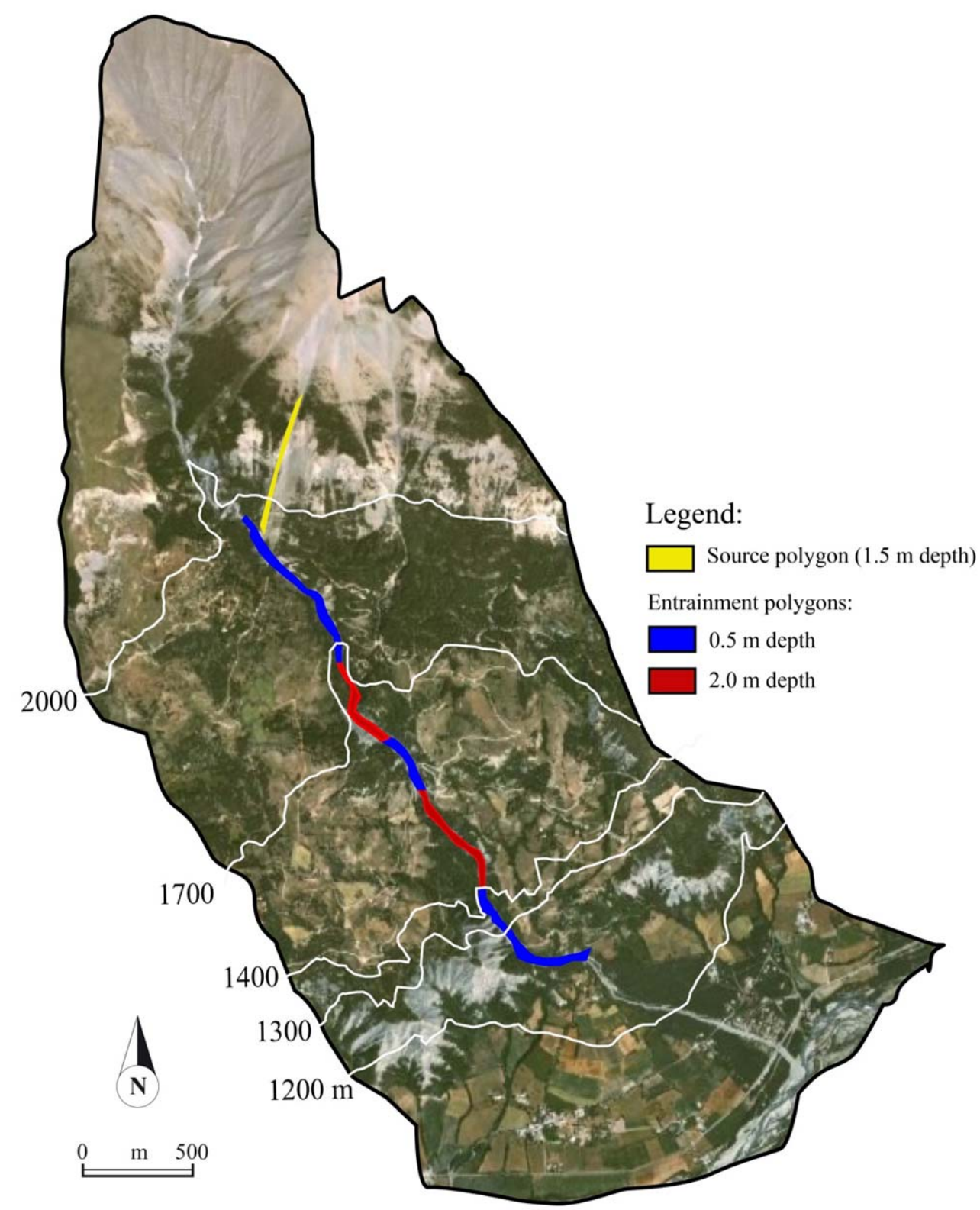

Fig. 5. Orthophotograph and boundary of the Faucon catchment, with the yellow polygon indicating the source area and the blue and red polygons indicating the $0.5 \mathrm{~m}$ and $2.0 \mathrm{~m}$ entrainment depths, respectively.

Equifinality states that there are many ways or paths that can lead to the same end (von Bertalanffy, 1968). Therefore, there is a possibility of reaching the same calibrated output using different combinations of input values. We tried in this research to avoid equifinality in order to come up with a single set of parameter values for the calibration. A parameterization analysis of the possible range of values for the Voellmy friction coefficient $\mu$, turbulent coefficient $\xi$ and the RAMMS entrainment coefficient $K$ was carried out through a literature review and subsequent modeling.

Sosio et al. (2008) have summarized the ranges of the Voellmy parameters for debris flows, determined from the back-analysis of hundreds of debris flow and avalanche events. Scotto di Santolo and Evangelista (2009) carried out a back-analysis of 57 debris flows in Italy using the Voellmy rheology with the 2-D DAN-W modeling software. Quan Luna et al. (2010) compiled a database of the back-analysis of 253 past landslide events, with $61 \%$ consisting of debris flows. A total of 152 from these were back-analyzed using the Voellmy rheology. They produced probability density functions for the two Voellmy parameters. The highest frequency for the friction coefficient $\mu$ was found to be between 0.05 and 0.2 , and the values for the turbulent coefficient $\xi$ were most frequent between 150 and $600 \mathrm{~m} \mathrm{~s}^{-2}$, peaking at 


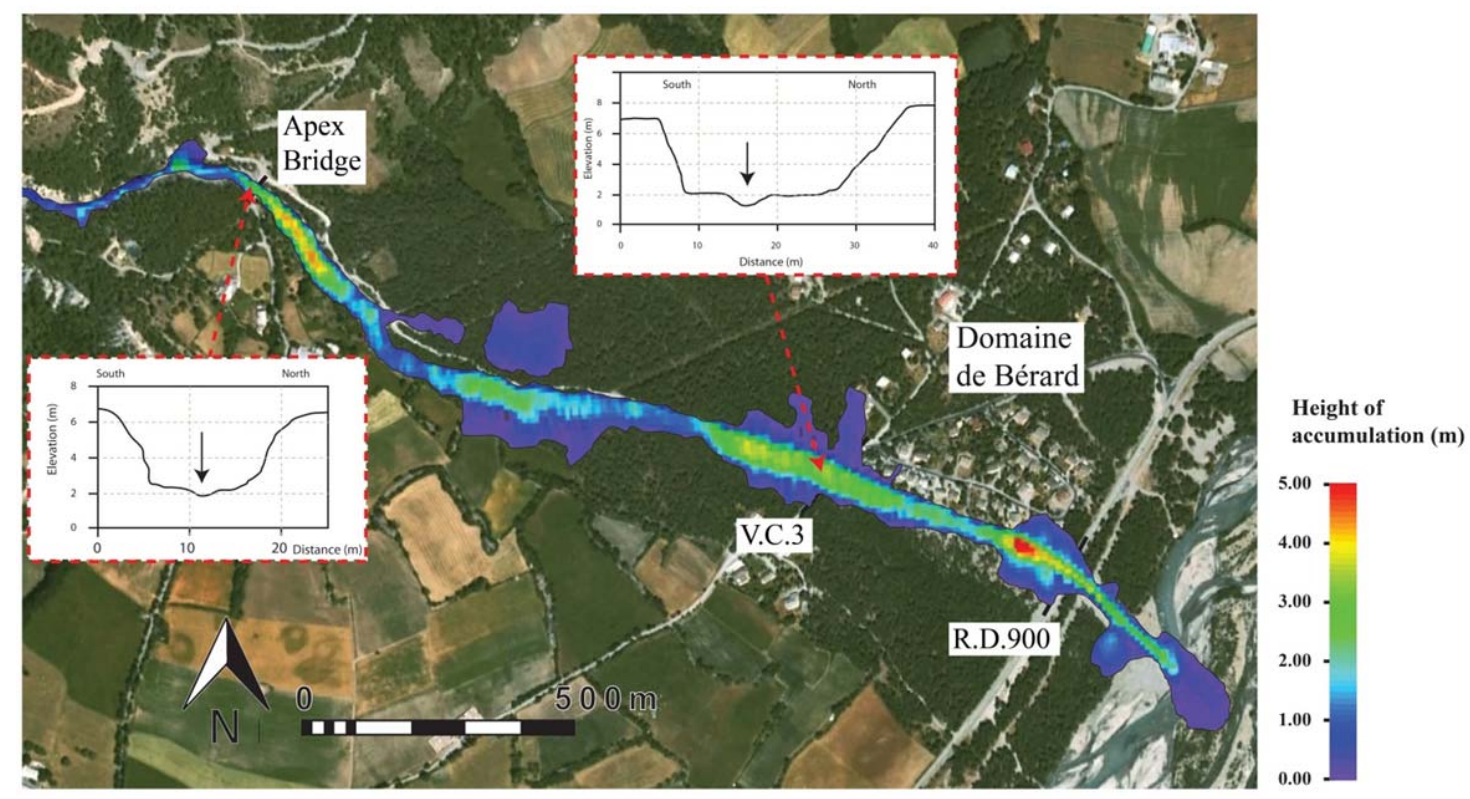

Fig. 6. Deposit heights of the RAMMS calibrated debris flow at the Faucon debris fan. The two cross sections represent the points used for model parameterization and calibration and are located inside the channel just before the Apex and V.C.3 Bridge.

$500 \mathrm{~m} \mathrm{~s}^{-2}$. Christen et al. (2010) studied the effects of the RAMMS entrainment coefficient $K$ on the entrainment process in snow avalanches. For $K=0$, there is no entrainment by the flow and for $K=1$, entrainment is nearly instantaneous.

The RAMMS model was run many times using a trial and error procedure in a systematic sampling method in order to optimize each parameter. Five calibration criteria were applied in order to compare with the values from the 2003 event: (1) spatial footprint of the run-out; (2) release volume; (3) final deposited volume; and (4) velocity and (5) flow depth at two control points located along the channel. These two points are situated inside the torrent channel just before the Bridge apex and the V.C. 3 Bridge; there cross sections are shown in Fig. 6. The reason for assessing the debris flow height and velocity at the debris fan apex is due to the fact that the apex is the start of the deposition zone on the fan and the apex itself contains an important bridge that conducts to settlements in the upper part of the Faucon catchment. If this bridge was to be damaged, then these settlements are cut off from the main valley road. The second location that is assessed is the V.C. 3 Bridge located at the upstream part of the housing "Domaine de Bérard". It is the first bridge near the village that could be damaged by a future debris flow. The 2003 debris flow struck this bridge, causing the deposition of debris into the village. Determining the debris flow velocity at these locations can be useful to calculate the impact pressure on the bridges crossing the channel. The reason for assessing the flow depth is to determine whether the de- bris flow overtops the channel banks, depositing debris on the bridges and surrounding settlements.

The best calibrated values found for the input parameters $\mu, \xi$ and $K$ are respectively $0.06,500 \mathrm{~m} \mathrm{~s}^{-2}$ and 1.0 . The output intensities of the RAMMS calibrated model were compared to the intensities of the 2003 event. The 2003 debris flow magnitude and intensity values were estimated in several previous studies (Remaître et al., 2005a, b, 2008; Remaître and Malet, 2010) partly using empirical methods (Rickenmann, 1999) and detailed post-event field mapping. The comparison and deviation from the 2003 event is shown in Table 1. As the intensities of the 2003 event are defined in terms of specific ranges, the modeled deviation is calculated in percentage difference from the lowest or highest value in the range, depending on whether the calibrated outputs are underestimated or overestimated from the 2003 debris intensities. All calibration criteria were met with one exception: the final criterion of similar flow heights could not be met. The model underestimates the debris flow heights at both the apex and V.C. 3 Bridge by 30 to $45 \%$ when compared with the 2003 event. Table 1 further indicates that the entrainment volume is approximately 4.5 times larger than the actual source volume, which shows how extremely important entrainment is to the production of the deposit volume on the debris fan.

The debris fan is considered a priority zone for landslide mitigation by the risk managers in the Barcelonnette Basin because of the elements at risk that are potentially affected by debris flows. Figure 6 shows the accumulated deposit height of the calibrated model at the debris fan. Starting at the fan 
Table 1. The 2003 debris flow intensity parameters vs. the calibrated model parameters

\begin{tabular}{llll}
\hline Intensity Parameters & 2003 Debris Flow & Calibrated Model & Deviation from 2003 \\
\hline Source volume & $14000-17000 \mathrm{~m}^{3}$ & $16728 \mathrm{~m}^{3}$ & $0 \%$ \\
Entrainment volume & $69000-78000 \mathrm{~m}^{3}$ & $75052 \mathrm{~m}^{3}$ & $0 \%$ \\
Total deposited volume & $83000-95000 \mathrm{~m}^{3}$ & $91780 \mathrm{~m}^{3}$ & $0 \%$ \\
Run-out distance & $4700 \mathrm{~m}$ & $4765 \mathrm{~m}$ & $+1.4 \%$ \\
Maximum debris flow height near fan apex & $5.0-6.0 \mathrm{~m}$ & $3.38 \mathrm{~m}$ & $-32.4 \%$ \\
Maximum debris flow height at the V.C. 3 Bridge & $5.0-6.0 \mathrm{~m}$ & $2.76 \mathrm{~m}$ & $-44.8 \%$ \\
Velocity near fan apex & $6.4-8.9 \mathrm{~m} \mathrm{~s}^{-1}$ & $7.19 \mathrm{~m} \mathrm{~s}^{-1} \mathrm{~s}$ & $0 \%$ \\
Velocity at the V.C. 3 bridge & $2.0-5.0 \mathrm{~m} \mathrm{~s}^{-1}$ & $2.59 \mathrm{~m} \mathrm{~s}^{-1}$ & $0 \%$ \\
\hline
\end{tabular}
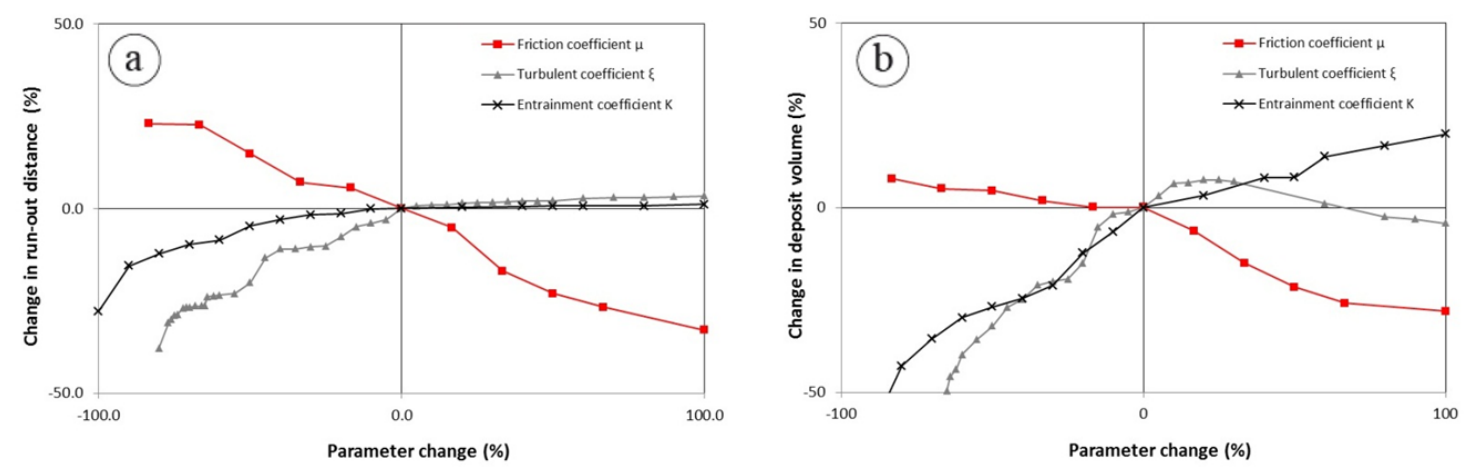

Fig. 7. Sensitivity to changes in model parameters: (a) run-out distance, (b) deposit volume.

apex, the deposits increase to approximately 4 to $5 \mathrm{~m}$ high and overtop the channel banks just after the apex. The maximum deposit height on top of the channel banks in the area next to the apex is around $0.5 \mathrm{~m}$. The channel deposit height at the V.C. 3 Bridge also seems to increase, with around 0.2 to $0.3 \mathrm{~m}$ of material deposited at the channel banks. The largest increase in accumulated deposits occurs before the R. D. 900 Bridge, reaching almost $5 \mathrm{~m}$ and covering an area of approximately $100 \mathrm{~m}$ wide around the main road. Finally, the Ubaye River is only partially blocked by debris, as the flow slows down and spreads laterally in the river's channel.

\section{Sensitivity analysis}

Although for RAMMS a sensitivity analysis was carried out by Christen et al. (2010), it was considered relevant to do this taking into account the ranges of values relevant for this study area. Three input parameters were used in the analysis: the friction coefficient $\mu, \mu$ the turbulent coefficient $\xi$, and the RAMMS entrainment coefficient $K$. Each input parameter was increased or decreased by a certain percentage from its original calibrated value using a systematic sampling method, while the other two input parameters were kept constant at their calibration values in order not to affect the sensitivity of the parameter being tested. For the friction coefficient $\mu$, the turbulent coefficient $\xi$ and the entrainment coef- ficient $K$, values ranging from 0.01 to $0.7,100$ to $3000 \mathrm{~m} \mathrm{~s}^{-2}$ and 0 to 5 were used, respectively. The ranges were also based on the previous discussed literature. A total of 120 debris flow run-outs were simulated within these parameter ranges. Four different outputs were assessed in the sensitivity analysis: the total run-out distance; the total deposit volume; the maximum debris flow height at the apex and the V.C. 3 Bridge; and the maximum debris flow velocity at both locations.

Figure 7a shows that the run-out distance has the highest rate of change, with an increase in the friction coefficient $\mu$. Changes in run-out to the turbulent coefficient $\xi$ and entrainment coefficient $K$ seem to be similar, with $\xi$ having a slightly stronger effect than the entrainment coefficient $K$. This result is in agreement with the study of Borstad and McClung (2009) who concluded that the friction coefficient $\mu$ affects the run-out distance and that the turbulent coefficient $\xi$ mainly influences the velocity of the flow. Figure $7 \mathrm{~b}$ indicates that the friction coefficient $\mu$ shows a similar trend for changes in debris flow deposit volume. However, the change in the entrainment coefficient has overall a clear and strong trend on the effect of the deposit volume, while the turbulent coefficient $\xi$ does not show such a clear trend despite its decreasing effect on deposit volumes.

Figure $8 \mathrm{a}-\mathrm{b}$ reveals that changes in the entrainment coefficient $K$ significantly change the debris flow height at the apex and even more at the V.C. 3 Bridge. Also, an increase in 

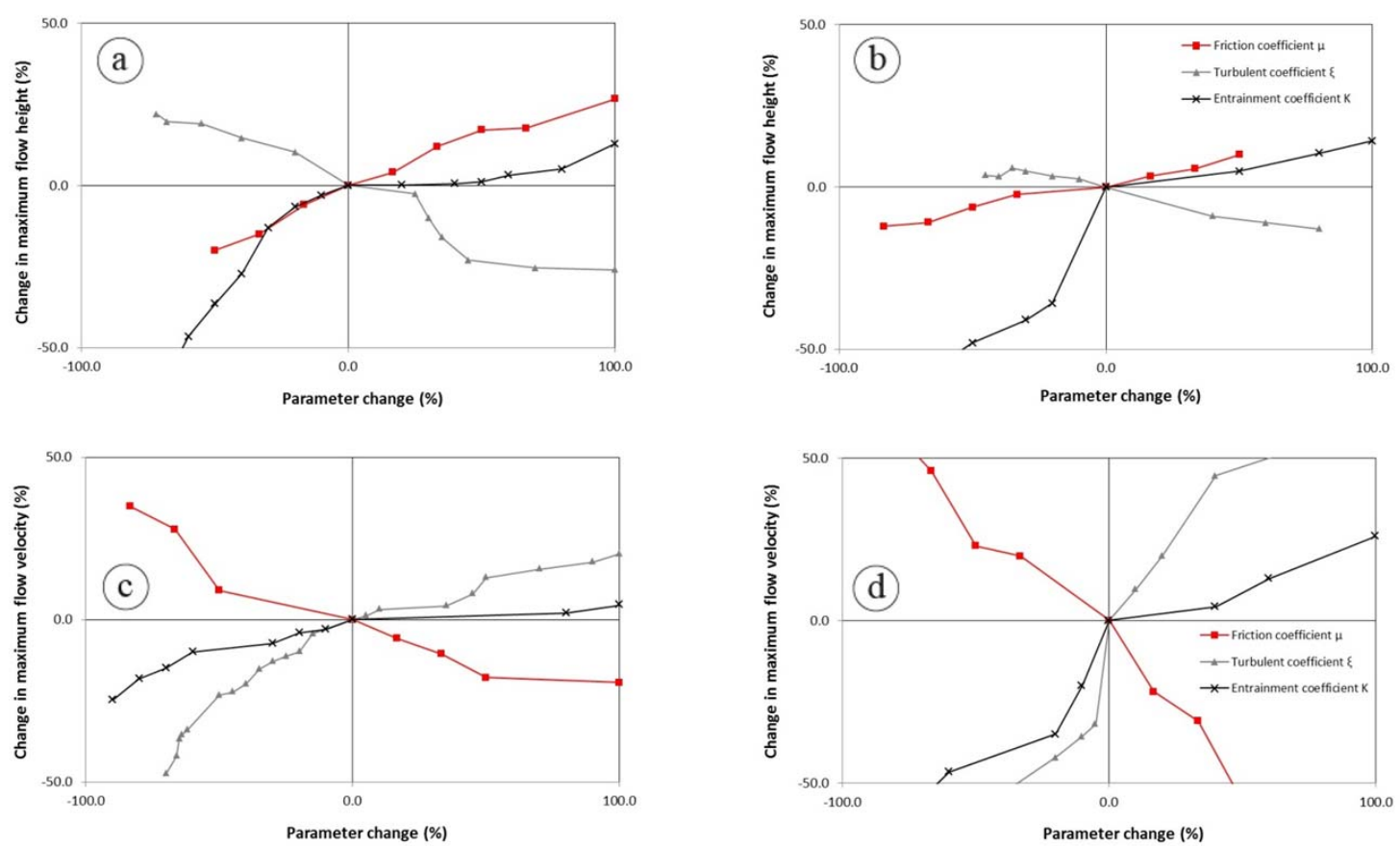

Fig. 8. Sensitivity of the maximum flow height at (a) the apex and the (b) Bridge VC3 and sensitivity of the maximum velocity at (c) the apex and (d) the Bridge VC3 to changes in the model parameters.

the friction coefficient $\mu$ significantly increases flow heights while the turbulent coefficient $\xi$ has the opposite effect. According to Fig. $8 \mathrm{c}-\mathrm{d}$, the overall rate of change in velocity at the V.C. 3 Bridge is higher than at the apex for all parameters, with the Voellmy turbulent coefficient $\xi$ having the strongest effect on the debris flow velocity at both control points. The friction coefficient $\mu$ has an opposite but significant effect where its increase causes a decrease in velocity. The increase in the entrainment coefficient $K$ and thus the amount of debris taken into the flow also substantially increases the velocity, with a similar trend to that of the turbulent coefficient $\xi$.

\section{Frequency analysis of the model outputs}

The results from the 120 model simulations were used to analyze the distribution of the outputs and to give an indication of the type of debris flow that would be more probable to occur based on the wide ranges used in the input parameters. All the modeled parameters from the 120 simulations, including the calibration modeling, were incorporated into the calculation of the cumulative frequency of the run-out distance within the channel from the source area to the Ubaye River. The cumulative frequency of debris flow occurrence is calculated by analyzing the number of run-outs that are shorter or equal to a specific distance from the source area. This was done by dividing the length of the channel into $10 \mathrm{~m}$ intervals.
The cumulative frequency of the debris flow height within the channel at the apex and the V.C. 3 Bridge is also calculated in order to assess what heights are most probable, given the input parameter ranges. The channel cross section from the bottom to the top is divided into $10 \mathrm{~cm}$ intervals for both locations. The height of each of the modeled debris flow reaching these locations within the channel is measured. Then the cumulative frequency of the debris flow height for each $10 \mathrm{~cm}$ interval is calculated.

Given a source volume of $16728 \mathrm{~m}^{3}$, a total available entrainment volume of $75052 \mathrm{~m}^{3}$ and the Voellmy and entrainment input parameter ranges obtained from the parameterization and sensitivity analysis, all 120 modeled debris flows reach at least a travel distance of $1000 \mathrm{~m}$ (Fig. 9a). A total of 89 debris flows reach the apex, traveling a distance of at least $3490 \mathrm{~m}$ from the source area. Furthermore, 70 debris flows reach the housing "Domaine de Bérard" at the V.C. 3 Bridge. Thus, more than half of all the modeled flows have a runout distance of at least $4240 \mathrm{~m}$, with the distribution having a mean run-out distance of $3929 \mathrm{~m}$. Figure 9a further shows that at the apex the run-out frequency of debris flows significantly starts to decrease. This is possibly due to the terrain, where the torrent starts to bend in an S-shape just before the apex thus decreases the flow velocity and the total number of debris flows reaching the apex.

A total of 18 flows out of the 89 that reach the apex have a maximum debris flow height above $5 \mathrm{~m}$ (Fig. 9b), thus overtopping the channel banks. The largest debris height modeled 

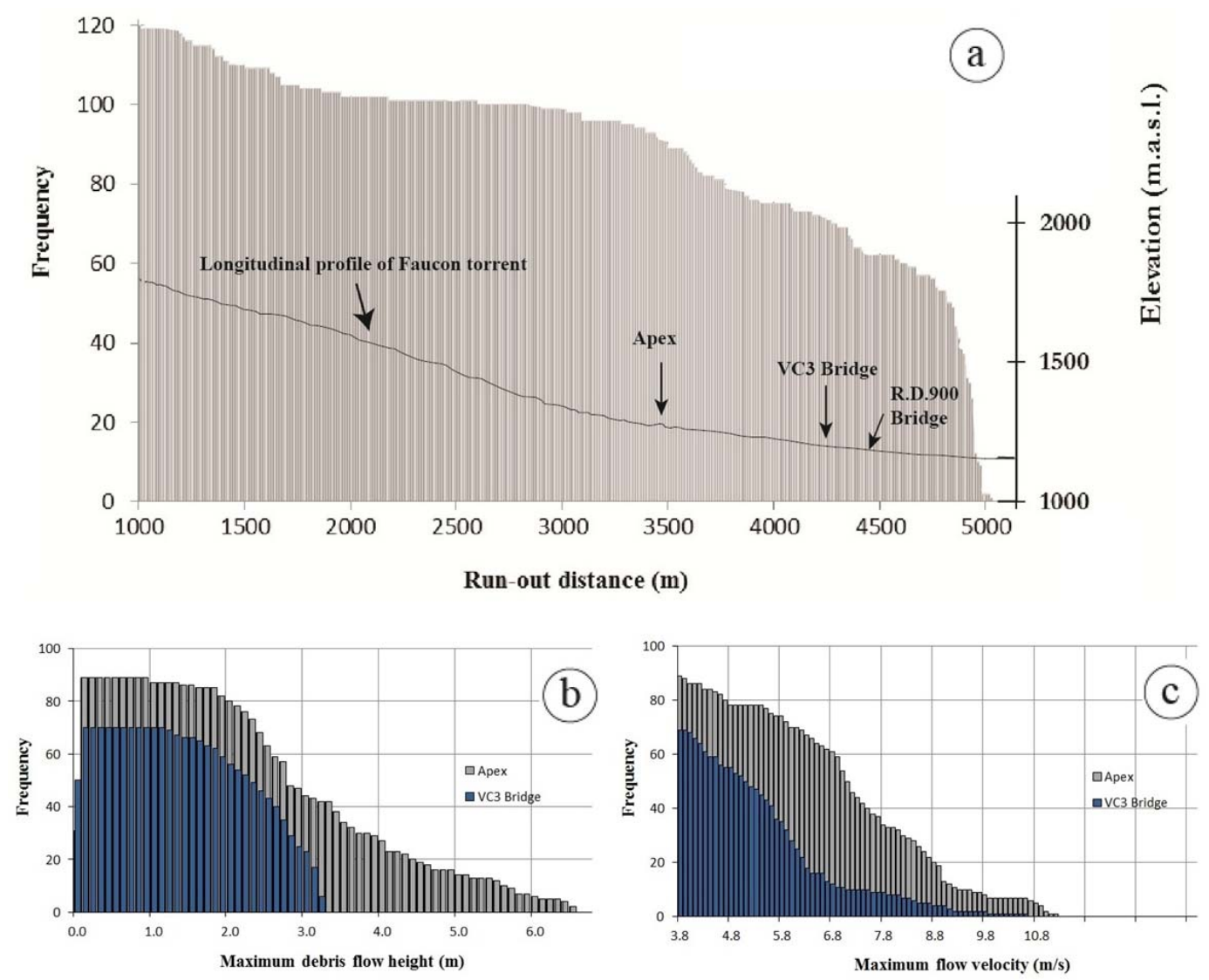

Fig. 9. Frequency distribution showing the number of modeled debris flows reaching a certain run-out distance, with a total of 120 modeled flows. (b) The frequency distribution of the maximum debris flow height and (c) the maximum flow velocity at the apex and VC3 Bridge control points.

at the apex is approximately $6.5 \mathrm{~m}$, which would cover the entire bridge at the apex with at least $1.5 \mathrm{~m}$ of debris, blocking off all traffic to the upper catchment. The 31 debris flows that do not reach the apex are also included in the frequency distribution. Figure $9 \mathrm{~b}$ also shows the frequency distribution of the modeled debris flow heights of the 70 flows that reach the V.C. 3 Bridge. There are no flows that have a flow height above the maximum channel depth of $5.5 \mathrm{~m}$. The actual deposition of debris around the V.C. 3 Bridge occurs slightly more upstream, causing the flow height to slightly decrease at the V.C. 3 Bridge location. The largest modeled flow height at the V.C.3 Bridge is approximately $3.2 \mathrm{~m}$. The distribution of the velocities for both locations (Fig. 9c) are similar, with the exception being that there are obviously less flows reaching the VC3 Bridge and the distribution at this location is more positively skewed to the right.

\section{Discussion and conclusions}

One of the main assumptions in the RAMMS model is that the flow is taken as a single-phase model with a constant
Voellmy rheology. This means there is no modeling of the separation and mixing between the solid and the fluid phase of the flow, which is one of the main disadvantages of singlephase models. Another important assumption was taking the triggered source volume as a single "block release" instead of using a hydrograph. Using hydrographs have been found to be useful with intense rainfall accumulation in channelized debris flows (Nakagawa and Takahashi, 1997; Hürlimann et al., 2003). They can also describe initial boundary conditions more accurately and can be adjusted to match observations of the flow in the field. Their advantages also include reducing the time to calculate the flow reaching the debris fan area.

The debris flow back-analysis has been carried out under environmental settings that have been altered since the 2003 event. The channel geometry used in the calibration is not identical to the 2003 geometry, as it was measured from recent field observations. This is especially the case at the area next to the VC3 Bridge and the Domaine de Bérard hamlet. There, the channel in 2003 was no wider than 8 to $10 \mathrm{~m}$ (Remaître, 2006; Beguería et al., 2009), compared to the almost $40 \mathrm{~m}$ width at this moment in time. There are several differences in the run-out between the 2003 debris flow 


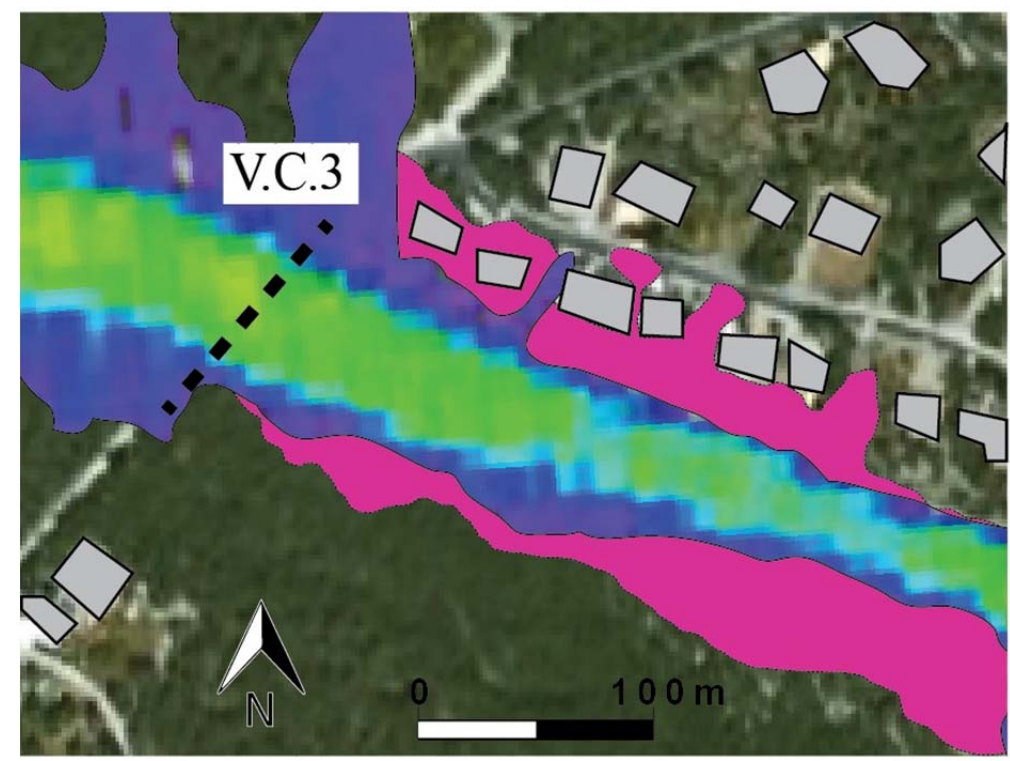

Legend:

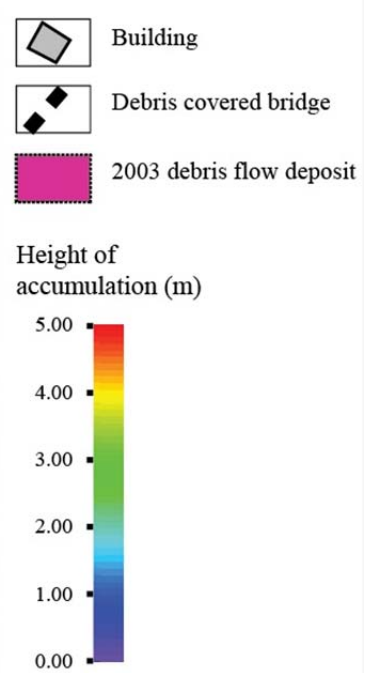

Fig. 10. Comparison of the observed 2003 debris flow deposition with the RAMMS back-calibrated model at the affected houses of the Domaine de Bérard hamlet near the VC3 Bridge.

(Fig. 3) and the modeled debris flow (Fig. 6). The modeled debris flow shows two locations before the flow reaches the village where very thin deposits $(10-30 \mathrm{~cm})$ occur in forested areas. These deposits coincide with possible changes in the channel slope gradient. As the slope gradient decreases, the velocity rapidly decreases, causing an increasing flow height where the flow starts to overtop the lateral banks. The maximum debris flow deposit height $(5 \mathrm{~m})$ is located approximately $50 \mathrm{~m}$ upstream of the R.D. 900 Bridge. This area also experiences a decrease in slope as the channel merges with the Ubaye River. The effects of channel widening are obvious, where the model has a wider flow and deposit inside the channel (Fig. 10) than the 2003 event. The modeled flow does not affect the housing "Domaine de Bérard" as it did in 2003. The deposit height near the houses is no more than 20 to $40 \mathrm{~cm}$, slightly touching the first few houses next to the flow path. According to the calibrated model, the flow height can still be higher further downstream, closer to the second bridge (R.D. 900).

An important advantage of RAMMS is the possibility of using entrainment during the run-out phase of the flow. Despite this advantage, the entrainment method used in RAMMS of dividing the transport zone into two averaged entrainment depths $(0.5$ and $2.0 \mathrm{~m})$ can also be subjected to an inaccuracy in the total amount of entrained debris. Averaging out the entrainment depth can affect the depositional pattern of the debris flow because some areas in the torrent had an entrainment depth of up to $4 \mathrm{~m}$ (Remaittre et al., 2009). If the entrainment depth did not have to be averaged to 0.5 $\mathrm{m}$ and $2.0 \mathrm{~m}$ and if more than two sets of entrainment shape files could be added to RAMMS, then the entrainment volume would possibly have a different value.

Figure 11 gives a good comparison between modeling with and without entrainment. Releasing the same source area without entrainment produces a debris flow with insignificant flow heights which starves out before ever reaching the fan apex. Modeling with entrainment gives reasonable results, especially at the front of the flow, again keeping in mind the change in channel width and depth since 2003. It is also important to note that a DEM depicts the topography at a particular point in time. The actual topography can change over a period of time by deposition and erosion of subsequent debris flows or by human modifications to the channel, such as the construction of dikes along the channel. This research has tried to incorporate these changes.

The resulting calibrated model has been able to reproduce the run-out distance and velocities within the range of the 2003 debris flow event at the Faucon catchment. The under prediction of the model to the debris heights is most likely due to changes in channel geometry since the last debris flow event. The under prediction can also be exaggerated by errors in the interpolation of the elevation data to produce the DEM and the low modeling resolution. Such errors can create rapid drops in elevation and inaccuracies in depicting the surface topography. However, it can be generally concluded that the construction carried out on the channel after 2003 is adequate for protecting the village from new debris flows with the same deposited volume of the 2003 debris flow. The modeling of the heights in the most recent environmental settings seems to indicate that the construction of the new mitigation works, which has resulted in an increase of the height of the 


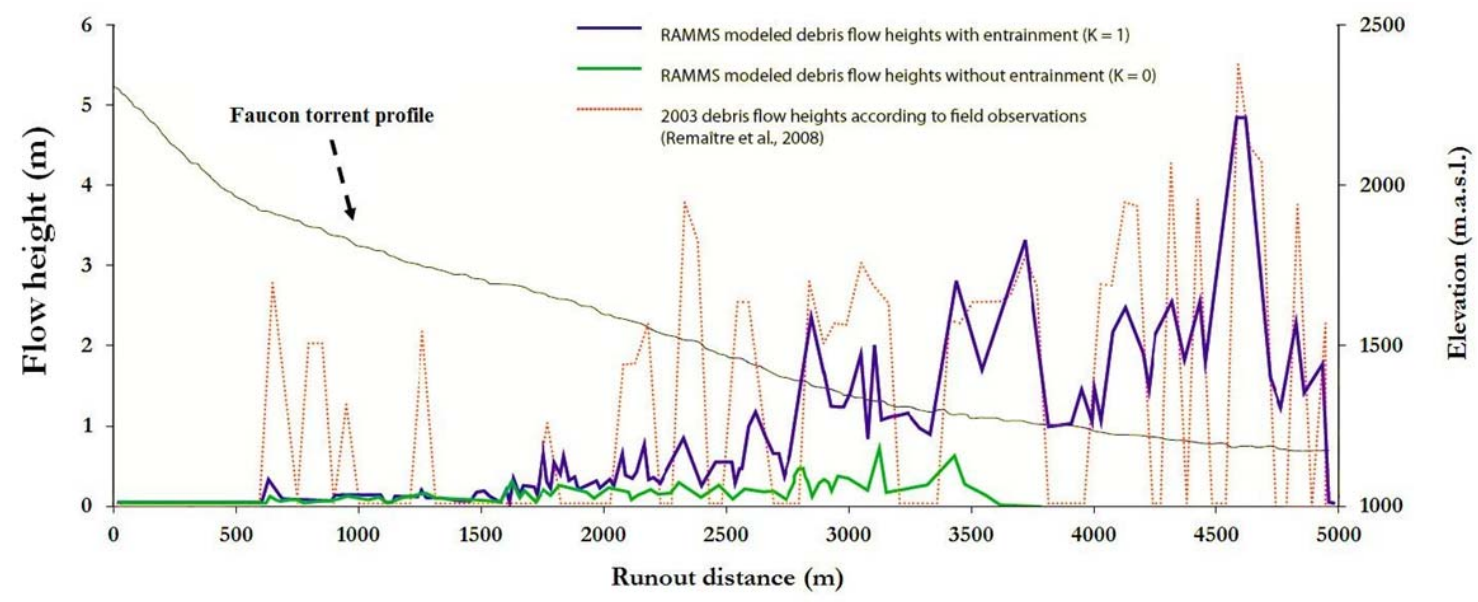

Fig. 11. Modeled profile of the debris flow heights (with and without entrainment) compared to the observed flow heights in the field.

channel banks and an increase of the channel width, may be appropriate to rapidly decrease the debris flow height from the apex to the village in future scenarios.

The method of applying calibration criteria has shown to be a good approach for obtaining the calibrated input parameters, thus narrowing down the possibility of having more than one combination of parameters giving the same output. Furthermore, the parameterization and calibration forms a good basis for the sensitivity analysis. However, there are also assumptions made in the analysis. The source volume and entrainment depths were kept constant throughout the analysis. Changes in these parameters would cause a shift in the initial boundary conditions and possibly give different results in final deposit volumes and intensities. Therefore, a sensitivity analysis of the change in deposit volume was carried out for the three input parameters. The run-out distances of the debris flows modeled in RAMMS were found to be most sensitive to the friction coefficient $\mu \mu$, while the velocities of the flows were most sensitive to the Voellmy turbulent coefficient $\xi$. The total deposit volume and debris flow heights were most sensitive to the RAMMS entrainment coefficient $K$. This further indicates the importance of incorporating entrainment in debris flow modeling, and characterizes its effect on the debris flow volume and height.

Finally, an analysis of the frequency distribution of the run-out distance, flow heights and velocities of a likely debris flow event can give indications of which areas are most likely to be affected and what the most likely flow intensities will be on element at risks. This type of frequency analysis can be an important first step to assess the spatial probability in future debris flow hazard assessments.

Acknowledgements. This work has been supported by the Marie Curie Research and Training Networks "Mountain Risks" (20072010, Contract MCRTN-35098) part of 6th Framework Program and by the PEOPLE Initial Training Network "CHANGES" (20112014, Grant Agreement No. 263953), part of the 7th Framework Program of the European Commission. The RAMMS modeling software was provided by the staff of the WSL/SLF Swiss Federal Institute for Snow Avalanche Research.

Edited by: A. Günther

Reviewed by: M. Hürlimann and one anonymous referee

\section{References}

Allen, S. K., Schneider, D., and Owens, I. F.: First approaches towards modelling glacial hazards in the Mount Cook region of New Zealand's Southern Alps, Nat. Hazards Earth Syst. Sci., 9, 481-499, doi:10.5194/nhess-9-481-2009, 2009.

Ayotte, D. and Hungr, O.: Calibration of a runout prediction model for debris-flows and avalanches, in: Debris-Flow Hazards Mitigation: Mechanics, Prediction, and Assessment: Proceedings of the Second International Conference on Debris-Flow Hazards Mitigation, edited by: Wieczorek, G. F. and Naeser, N. D., Taipei, Taiwan, 16-18 August 2000, 505-514, 2000.

Bartelt, P., Salm, B., and Gruber, U.: Calculating dense-snow avalanche runout using a Voellmy-fluid model with active/passive longitudinal straining, J. Glaciol., 45, 242-254, 1999.

Beguería, S., Van Asch, Th. W. J., Malet, J.-P., and Gröndahl, S.: A GIS-based numerical model for simulating the kinematics of mud and debris flows over complex terrain, Nat. Hazards Earth Syst. Sci., 9, 1897-1909, doi:10.5194/nhess-9-1897-2009, 2009.

Borstad, C. P. and McClung, D. M.: Sensitivity analyses in snow avalanche dynamics modeling and implications when modeling extreme events, Can. Geotech. J., 46, 1011-1023, 2009.

Bühler, Y., Christen, M., Kowalski, J., and Bartelt, P.: Sensitivity of snow avalanche simulations to digital elevation model quality and resolution, Ann. Glaciol., 52, 72-80, 2011.

Casteller, A., Christen, M., Villalba, R., Martínez, H., Stöckli, V., Leiva, J. C., and Bartelt, P.: Validating numerical simulations of snow avalanches using dendrochronology: the Cerro Ventana 
event in Northern Patagonia, Argentina, Nat. Hazards Earth Syst. Sci., 8, 433-443, doi:10.5194/nhess-8-433-2008, 2008.

Cesca, M. and D'Agostino, V.: Comparison between FLO-2-D and RAMMS in debris-flow modelling: a case study in the Dolomites, edited by: de Wrachien, D., Brebbia, C. A., and Lenzi, M. A., Monitoring, Simulation, Prevention and Remediation of Dense Debris Flows II, 60, 197-206, 2006.

Chen, J. and Lee, C. F.: Landslide mobility analysis using Madflow, in: The 2007 International Forum on Landslide Disaster Management, edited by: Ho, K. and Li, V., Hong Kong, 10-12 December 2007, 2, 857-874, 2007.

Christen, M., Kowalski, J., and Bartelt, P.: RAMMS: Numerical simulation of dense snow avalanches in three-dimensional terrain, Cold Reg. Sci. Technol., 63, 1-14, 2010.

Corominas, J.: The angle of reach as a mobility index for small and large landslides, Can. Geotech. J., 33, 260-271, 1996.

Coussot, P.: Mudflow Rheology and Dynamics (IAHR monograph), Balkema, Rotterdam, Netherlands, 260 pp., 1997.

Crosta, G. B., Imposimato, S., and Roddeman, D. G.: Numerical modelling of large landslides stability and runout, Nat. Hazards Earth Syst. Sci., 3, 523-538, doi:10.5194/nhess-3-5232003, 2003.

Crosta, G. B., Imposimato, S., and Roddeman, D.: Numerical modelling of entrainment-deposition in rock and debris-avalanches, Eng. Geol., 109, 135-145, 2009.

D'Ambrosio, D., Di Gregorio, S., and Iovine, G.: Simulating debris flows through a hexagonal cellular automata: SCIDDICA S3-hex, Nat. Hazards Earth Syst. Sci., 3, 545-559, 2003, http://www.nat-hazards-earth-syst-sci.net/3/545/2003/.

Denlinger, R. P. and Iverson, R. M.: Granular avalanches across irregular three-dimensional terrain: 1 . theory and computation, $\mathrm{J}$. Geophys. Res., 109, 14 pp., 2004.

Fischer, J.-T., Kowalski, J., and Pudasaini, S. P.: Topographic curvature effects in applied avalanche modeling, Cold Reg. Sci. Technol., 74-75, 21-30, 2012.

Flageollet, J.-C., Maquaire, O., Martin, B., and Weber, D.: Landslides and climatic conditions in the Barcelonnette and Vars basins (Southern French Alps, France), Geomorphology, 30, 6578, 1999.

Graf, C. and McArdell, B. W: Debris-flow monitoring and debrisflow runout modelling before and after construction of mitigation measures: an example from an instable zone in the Southern Swiss Alps, in: La géomorphologie alpine: entre patrimoine et contrainte. Actes du colloque de la Société Suisse de Géomorphologie, edited by: Lambiel, C., Reynard, E. and Scapozza, C., 3-5 September 2009, Olivone, Université de Lausanne Institut de Géographie, Lausanne, 245-258, 2011.

Hsu, K. J.: Albert Heim: observations on landslides and relevance to modern interpretations, in: Rockslides and Avalanches, edited by: Voight, B., Elsevier, Amsterdam, Netherlands, 71-93, 1978.

Hungr, O.: A model for the runout analysis of rapid flow slides, debris flows and avalanches, Can. Geotech. J., 32, 610-623, 1995.

Hungr, O. and McDougall, S.: Two numerical models for landslide dynamic analysis, Comput. Geosci., 35, 978-992, 2009.

Hürlimann, M., Rickenmann, D., and Graf, C.: Field and monitoring data of debris- flow events in the Swiss Alps, Can. Geotech. J., 40, 161-175, 2003.

Hürlimann, M., Medina, V., Bateman, A., Copons, R. and Altimir, J.: Comparison of different techniques to analyse the mobility of debris flows during hazard assessment-Case study in La Comella catchment, Andorra, in: Debris-Flow Hazard Mitigation: Mechanics, Prediction and Assessment, edited by: Chen, C.-L. and Major, J. J., Millpress, Netherlands, 411-422, 2007.

Hussin, H. Y.: Probabilistic run-out modeling of a debris flow in Barcelonnette, France, M.Sc. thesis, Faculty of Geo-Information Science and Earth Observation (ITC), University of Twente, Enschede, Netherlands, 94 pp., 2011.

Iverson, R. M.: The physics of debris flows, Rev. Geophys., 35, 245-296, 1997.

Kappes, M. S., Malet, J.-P., Remaître, A., Horton, P., Jaboyedoff, M., and Bell, R.: Assessment of debris-flow susceptibility at medium-scale in the Barcelonnette Basin, France, Nat. Hazards Earth Syst. Sci., 11, 627-641, doi:10.5194/nhess-11-627-2011, 2011.

Kowalski, J.: Two-Phase Modeling of Debris Flows, Ph.D. thesis, Eidgenössische Technische Hochschule (ETH), Zurich, Switzerland, 135 pp., 2008.

Malet, J.-P.: Data Acess Barcelonnette area, http://eost.u-strasbg.fr/ omiv/data_access_Barcelonnette.php, 2010.

Malet, J.-P., Remaître, A., and Maquaire, O.: Runout modeling and extension of the threatened area associated with muddy debris flows, Geomorphologie, 3, 1950-1210, 2004.

Malet, J.-P., Laigle, D., Remaître, A., and Maquaire, O.: Triggering conditions and mobility of debris flows associated to complex earthflows, Geomorphology, 66, 215-235, 2005.

Maquaire, O., Malet, J.-P., Remaître, A., Locat, J., Klotz, S., and Guillon, J.: Instability conditions of marly hillslopes: towards landsliding or gullying? The case of the Barcelonnette Basin, South East France, Eng. Geol., 70, 109-130, 2003.

McDougall, S. and Hungr, O.: Dynamic modelling of entrainment in rapid landslides, Can. Geotech. J., 42, 1437-1448, 2005.

Medina, V., Hürlimann, M., and Bateman, A.: Application of FLATModel, a 2-D finite volume code, to debris flows in the northeastern part of the Iberian Peninsula, Landslides, 5, 127-142, 2008.

Nakagawa, H. and Takahashi, T.: Estimation of a debris flow hydrograph and hazard area, in:Proceedings of the First International Conference on Debris-Flow Hazard Mitigation: Mechanics, Prediction, and Assessment, edited by: Chen, C.-L., 7-9 August 1997, San Francisco, California, 64-73, 1997.

O'Brien, J. S., Julien, P. Y., and Fullerton, W. T.: Two-dimensional water flood and mudflow simulation, J. Hydraul. Eng., 119, 244261, 1993.

Pastor, M., Haddad, B., Sorbino, G., Cuomo, S., and Drempetic, V.: A depth-intergrated, coupled SPH model for flow-like landslides and related phenomena, Int. J. Numer. Anal. Meth. Geomech., 33, 143-172, 2009.

Pirulli, M. and Sorbino, G.: Assessing potential debris flow runout: a comparison of two simulation models, Nat. Hazards Earth Syst. Sci., 8, 961-971, doi:10.5194/nhess-8-961-2008, 2008.

Quan Luna, B.: Assessment and modelling of two lahars caused by "Hurricane Stan" at Atitlan, Guatemala, October 2005, MS.c. thesis, University of Oslo, Oslo, Norway, 2007.

Quan Luna, B., van Westen, C. J., Jetten, V., Cepeda, J., Stumpf, A., Malet, J.-P., Medina-Cetina, Z., and van Asch, T. W. J.: A preliminary compilation of calibrated rheological parameters used in dynamic simulations of landslide run - out, in: Mountain risks: bringing science to society: Proceedings of the Mountain Risks International Conference, edited by: Malet, J.-P., Glade, T., and 
Casagli, N., Firenze, Italy, CERG, Strasbourg, 255-260, 2010.

Quan Luna, B., Blahut, J., van Westen, C. J., Sterlacchini, S., van Asch, T. W. J., and Akbas, S. O.: The application of numerical debris flow modelling for the generation of physical vulnerability curves, Nat. Hazards Earth Syst. Sci., 11, 2047-2060, doi:10.5194/nhess-11-2047-2011, 2011.

Quan Luna, B., Remaitre, A., van Asch, T. W. J., Malet, J.-P., and van Westen, C. J.: Analysis of debris flow behavior with a one dimensional run - out model incorporating entrainment, Eng. Geol., 128, 63-75, 2012.

Remaître, A.: Morphologie et dynamique des laves torrentielles: application aux torrents des Terres Noires du bassin de Barcelonnette (Alpes du Sud), Ph.D. thesis, University of Caen BasseNormandie, Caen, France, 487 pp., 2006.

Remaître, A. and Malet, J.-P.: The effectiveness of torrent check dams to control channel instability: example of debris-flow events in clay shales, in: Check dams, morphological adjustements and erosion control in torrential streams, edited by: Garcia, C. C. and Lenzi, M. A., Nova Science Publishers Inc., New York, 211-237, 2010.

Remaître, A., Malet, J.-P. and Maquaire, O.: Morphology and sedimentology of a complex debris flow in a clay-shale basin, Earth Surf. Proc. Land., 30, 339-348, 2005a.

Remaître, A., Malet, J.-P., Maquaire, O., Ancey, C., and Locat, J.: Flow behaviour and runout modelling of a complex debris flow in a clay-shale basin, Earth Surf. Proc. Land., 30, 479-488, 2005 b.

Remaître, A., van Asch, Th. W. J., Malet, J.-P., and Maquaire, O.: Influence of check dams on debris-flow run-out intensity, Nat. Hazards Earth Syst. Sci., 8, 1403-1416, doi:10.5194/nhess-81403-2008, 2008.

Remaître, A., Malet, J.-P., and Maquaire, O.: Sediment budget and morphology of the 2003 Faucon debris flow (South French Alps): scouring and channel-shaping processes, edited by: Malet, J.-P., Remaître, A., and Boogard, T. A., in: Proceedings of the International Conference "Landslide Processes: from geomorpholgic mapping to dynamic modelling", CERG, Strasbourg, France, 7580, 2009.

Rickenmann, D.: Empirical Relationships for Debris Flows, Nat. Hazards, 19, 47-77, 1999.

Rickenmann, D.: Runout prediction methods, in: Debris-flow Hazard and Related Phenomena, edited by: Jakob, M. and Hungr, O., Springer-Praxis, Chichester, UK, 305-324, 2005.

Rickenmann, D., Laigle, D., McArdell, B. W., and Hübl, J.: Comparison of 2-D debris-flow simulation models with field events, Comput. Geosci., 10, 241-264, 2006.
Rickenmann, D., Weber, D., and Stepanov, B.: Erosion by debris flows in field and laboratory experiments, in: Proceedings of the Third International Conference on Debris-Flow Hazard Mitigation: Mechanics, Prediction and Assessment, edited by: Rickenmann, D. and Chen, L. C., 10-12 September, Davos, Switzerland, Milpress, Rotterdam, Netherlands, 883-894, 2003.

Salm, B.: Flow, flow transition and runout distances of flowing avalanches, Ann. Glaciol., 18, 221-226, 1993.

Sassa, K.: Geotechnical model for the motion of landslides, in: Proceedings of the 5th International Symposium on Landslides, 1015 July, Lausanne, Switzerland, 37-55, 1988.

Schneider, D., Bartelt, P., Caplan-Auerbach, J., Christen, M., Huggel, C., and McArdell, B. W.: Insights into rock-ice avalanche dynamics by combined analysis of seismic recordings and a numerical avalanche model, J. Geophys. Res., 115, 20 pp., doi:10.1029/2010JF001734, 2010.

Scotto di Santolo, A. and Evangelista, A.: Some observations on the prediction of the dynamic parameters of debris flows in pyroclastic deposits in the Campania region of Italy, Nat. Hazards, 50, 605-622, 2009.

Sosio, R., Crosta, G. B. and Hungr, O.: Complete dynamic modeling calibration for the Thurwieser rock avalanche (Italian Central Alps), Eng. Geol., 100, 11-26, 2008.

Sovilla, B., Burlando, P., and Bartelt, P.: Field experiments and numerical modelling of mass entrainment in snow avalanches, J. Geophys. Res., 111, 16 pp., doi:10.1029/2005JF000391, 2006.

Takahashi, T.: A Review of Japanese Debris Flow Research, International Journal of Erosion Control Engineering, ASCE, 2, 1-14, 2009.

van Asch, T. W. J., Malet, J.-P., Remaître, A., and Maquaire, O.: Numerical modelling of the run-out of a muddy debris flow, in: The effect of rheology on velocity and deposit thickness along the run-out track, Proceedings of the 9th International Symposium on Landslides, edited by: Lacerda, W., 28 June -2 July 2004, Rio de Janeiro, Brazil, 1433-1438, 2004.

Voellmy, A.: On the destructive force of avalanches, SLF, Davos, Switzerland, 190 pp., 1955.

von Bertalanffy, L.: General systems theory: Foundations, Development, Applications, George Braziller Inc., New York, 296 pp., 1968. 